\title{
PSICODRAMA ON-LINE COM CRIANÇAS E O MÉTODO DO SANDPLAY PSICODRAMÁTICO
}

\author{
Vanessa Ramalho Ferreira Strauch 1,2,* (D)
}

\begin{abstract}
RESUMO
A psicoterapia virtual foi intensificada na pandemia 2020. Objetivamos refletir sobre os desafios do método psicodramático com crianças na modalidade on-line incluindo etapas, ferramentas e constructo télico. Identificamos possibilidades terapêuticas adaptativas no método do sandplay psicodramático e dificuldades na sustentação do conflito, continência afetiva, conectividade, privacidade e confidencialidade. A teoria socionômica com suas técnicas psicodinâmicas traz embasamento para a prática à distância. Sinalizamos o Eu Curador Interno da criança (natureza espontâneo criativa) como um guia norteador do manejo clínico.
\end{abstract}

PALAVRAS-CHAVE: Psicodrama infantil; Modalidade on-line; Sandplay psicodramático.

\section{ONLINE PSYCHODRAMA WITH CHILDREN AND THE PSYCHODRAMATIC SANDPLAY METHOD}

\begin{abstract}
Virtual psychotherapy was intensified in the pandemic's 2020. We aim to reflect on the challenges of the psychodramatic method with children in the online modality including the steps, tools and the tele construct. We identified adaptive therapeutic possibilities in the psychodramatic sandplay method and difficulties in sustaining the conflict, affective continence, connectivity, privacy and confidentiality. Socionomic theory with its psychodynamic techniques provides a foundation for distance practice. We signal the child's Internal Healing Self (spontaneous creative nature) as a guiding guide for clinical management.
\end{abstract}

KEYWORDS: Child psychodrama; Online modality; Psychodramatic sandplay.

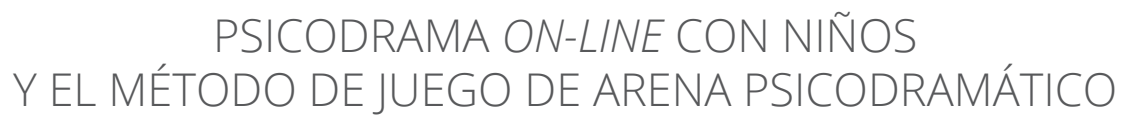

\section{RESUMEN}

La psicoterapia virtual se intensificó en la pandemia 2020. Nuestro objetivo es reflexionar sobre los desafíos del método psicodramático con niños en la modalidad on-line, incluyendo pasos, herramientas y el teleconstructo. Identificamos posibilidades terapéuticas adaptativas en el método del juego de arena psicodramático y dificultades para sostener el conflicto, la continencia afectiva, la conectividad, la privacidad y la confidencialidad. La teoría socionómica con sus técnicas psicodinámicas proporciona una base para la práctica a distancia. Señalamos al Yo de Sanación Interna del niño (naturaleza creativa espontánea) como guía para el manejo clínico.

PALABRAS-CLAVE: Psicodrama infantil; Modalidad on-line; Juego de arena psicodramático.

\footnotetext{
1.PROFINT - Profissionais Integrados - Aracaju (SE), Brasil.

2.Universidade Tiradentes - Aracaju (SE), Brasil.

*Autora correspondente: ramalhonessa@gmail.com

Editora de seção: Graziela Gatto

Recebido: 14 Dez 2020 | Aceito: 19 Mar 2021
} 


\section{INTRODUÇÃO: A INTERNET CONECTANDO NOSSAS VIDAS}

A internet chegou ao Brasil na década de 1990, e ao longo do tempo foi se alargando, alastrando e capilarizando, conquistando crianças e adultos como adeptos. Segundo pesquisas do IBGE, em 2018, sua penetração domiciliar em nosso país era de 79,1\%; já nas áreas urbanas era de 83,9\%. Então, uma parcela da população não está na faixa da inclusão digital. Porém, alguns destes também têm acesso em seus locais de trabalho ou públicos. Tal intensificação culminou no Marco Civil da Internet, por meio da Lei n. ${ }^{\circ}$ 12.965/2014, que regula o uso por meio da previsão de princípios, garantias, direitos e deveres na rede, bem como diretrizes para a atuação do Estado. Pouco antes disso, a Resolução CFP n.o 011/2012 passou a regulamentar os serviços psicológicos realizados por meios tecnológicos de comunicação a distância. Segundo dados da pesquisa TIC Kids Online Brasil (2014), entre crianças e adolescentes de 9 a 14 anos, os equipamentos mais utilizados são celular (82\%), computador de mesa (56\%), notebook (36\%), videogame (12\%) e televisão (5\%). Já o principal local de acesso à internet varia do quarto e sala à escola — inclusive, a população de 11 a 17 anos foi chamada de "geração do quarto" em 2015, pelo neuropsicólogo pernambucano Hugo Monteiro Ferreira (Coutinho, 2019). Na minha adolescência, fiquei encantada com a possibilidade de ver e conversar com familiares que moravam em outro país, mas, tempos depois, profissionalmente resistia a realizar atendimentos psicológicos por telas, pelo computador, tablet ou celular.

Segundo Fleury (2020), o uso das tecnologias com internet para atendimentos psicológicos tem sido chamado de “telepsicologia” pela APA (2013) e “telepsicoterapia” por Judge at al. (2011). Há décadas a “telemedicina” também vem tentando assistir pessoas em áreas distantes, com difícil acessibilidade e com dificuldades de deambular, inclusive em programas de políticas públicas como o Telessaúde. Ronaldo Pamplona da Costa e Carlos Borba (2005) criaram o termo "telepsicodrama" para representar a ferramenta de vídeopsicodramas pedagógicos, partindo dos experimentos de Moreno na década de 1920, com gravações de dramatizações de conflitos, para demonstrar o método sociopsicodramático da Socionomia em rádio, televisão e cinema. No jornal digital Agência USP de Notícias (Cruz, 2010), o telepsicodrama é citado como um recurso didático de metodologia ativa. Consiste em uma sessão de psicodrama gravada em vídeo com qualidade para exibição em circuitos de TV, tendo em vista abranger um público maior de pessoas do que aquelas que participaram diretamente da dramatização, com os benefícios do processo de ensino/aprendizagem. Nesse caso, o enfoque será socioeducacional, partindo de uma temática coletiva com publicização pré-acordada com o grupo. Já no psicodrama on-line com enfoque psicoterápico, sua gravação tem proibição ética, atualmente. Ademais, a bidirecionalidade da comunicação pela internet coloca em questão desafios interpessoais e de manejo clínico.

Com a pandemia do coronavírus em 2020, houve significativo aumento da comunicabilidade virtual nas relações interpessoais, do home-office e dos atendimentos mediados por tecnologias da informação e comunicação (TICs). Faro et al. (2020) analisam as consequências das medidas sanitárias adotadas, como distanciamento social, quarentena e isolamento, enfocando as repercussões e a emergência do cuidado em saúde mental, tanto aquele prestado pela Psicologia como o oferecido pelos demais profissionais de saúde, de modo a minimizar os impactos negativos da crise e atuar preventivamente. Citam nas pesquisas o aumento de quadros como depressão, ansiedade, estresse, transtorno do pânico, insônia, medo, raiva, vulnerabilidade ao adoecimento, relatos de tédio, solidão, estresse pós-traumático, sintomas somáticos, ruminação, diminuição da concentração, mau humor e perda de energia, mais o aguçamento das preocupações consigo e com os outros, uma intensificação de sintomas ligados ao enlutamento pessoal e coletivo e à sobrecarga emocional, física e de papéis sociais. De fato, vivenciamos uma sobreposição de papéis, todos sendo atuados num mesmo local: em casa, o que exige (re)adaptação.

Defendemos, de acordo com Moreno (1975, p. 80), uma filosofia do Ato Criador, na qual se interpretam e elaboram ações de correção antimecânica, que são criações realizadas com técnicas de improvisação de acordo com o momento relacional. Tais qualidades criadoras encontram-se à disposição no sistema nervoso do homem, mas também são advindas da convergência e confluência espontânea de elementos subconscientes, conscientes, emocionais, intelectuais e espirituais. Para ele, as características principais de um ato criativo são a espontaneidade, sensação de surpresa, irrealidade/ficção e singularidade/originalidade. $\mathrm{O}$ ator, autor e criador de sua própria história precisará resgatar sua capacidade de expressividade para aprender a criar respostas mais saudáveis, os "criatoflexos". 
Segundo Moreno (como citado em Ramalho, 2011), são recursos inatos do ser humano a sensibilidade, criatividade e espontaneidade (fator E). Esta última é um catalizador de estado fluente com altos e baixos, originalidades e adequações, forças libertárias e conservadoras. A espontaneidade a ser resgatada e treinada tem como características a originalidade, a qualidade dramática (vivacidade e novidade), a criatividade (novas transformações) e a adequação da resposta. Então ela é a capacidade de agir diante de situações antigas, novas e imprevistas, de forma variada, adequada e criativa, ao invés de repetidamente. A repetição cristaliza o comportamento, e o embotamento da espontaneidade adoece o sujeito. Outro conceito essencial é o de tele, que Moreno descreve, em 1934, como um sentimento mútuo projetado a distância, uma empatia em via dupla, um fator sociogravitacional que possibilita percepção interna mútua e verdadeira, que acreditamos contribuir para a cocriação espontânea na relação terapeuta-cliente em seus aspectos coconscientes e coinconscientes.

Partindo da visão moreniana de homem enquanto um "gênio criador" com centelha divina inata, acreditamos no Eu Curador Interno do sujeito atuando em cada etapa do ciclo da vida, buscando se adaptar, se adequar aos desafios e encontrar soluções, saídas mais saudáveis e viáveis diante dos problemas e das crises. O diretor de psicodrama e psicoterapeuta infantil estará ao lado e como facilitador para o aquecimento da espontaneidade desse Eu Curador Interno da criança (Strauch, 2020). Por isso, quando a criança sugere algo e nos guia durante a sessão, entendemos que seu protagonismo está caminhando em direção à sua cura interior e ao cuidado do seu Eu ferido. Ela está guiando a experimentação de seus papéis e da atuação do seu mundo imaginário.

Nossa finalidade terapêutica junto ao público infantil, tanto na modalidade presencial quanto na on-line, será a busca por relações mais télicas e espontâneas, capazes de perceber melhor o outro e reagir criativamente aos conflitos de forma condizente com o contexto e as possibilidades de encontro das verdades existenciais de cada um.

Moreno (1959/1974), quando relata o caso Karl, de 5 anos, atendido em 1922, reforça a importância da entrevista prévia com pais/responsáveis e que, quando necessário, devem ser incluídos no tratamento tanto genitores como irmãos ou outros familiares significativos na rede social do cliente. Afirma que castigos domésticos não são eficientes, não trazem mudança de comportamento. No trabalho com crianças, utilizou sempre o método do psicodrama simbólico para propiciar uma "receptividade espontânea para correções" no comportamento infantil. Segundo ele, o princípio do tratamento é representar a situação conflitiva ou traumática central em inúmeros ensaios e versões, para reduzir a tensão angustiada da criança e o choque do inesperado, com a presença de um terapeuta e auxiliares. Percebemos que o que ele chama de "psicodrama simbólico" envolve o lúdico, o brincar, a corporeidade, as dramatizações (teatro da vida) em realidade suplementar e as representações simbólicas das situações conflitivas de vida feitas por egos auxiliares. Cukier (1992) traz a adaptação ao contexto do psicodrama bipessoal, sem terapeutas auxiliares. Na clínica infantil, entendemos que, nessa modalidade individual (a dois), quem exerce o papel de ego auxiliar, entrando no lugar dos "eus significativos do cliente", é o corpo do próprio cliente, o corpo do terapeuta diretor ou o manejo clínico deste utilizando-se de objetos intermediários, como fantoches, bonecos, miniaturas, almofadas, tecidos e outros objetos inanimados mais ou menos estruturados para representação. Ora o diretor dará voz a esses personagens, ora a própria criança dará voz a diversos personagens, sejam eles concretos ou abstratos, vivos ou não vivos.

Então, percebemos que a representação simbólica em ação, o "como se psicodramático" em realidade suplementar para realização simbólica, o faz de conta experimentado numa situação conflitiva, será a essência do psicodrama, e especialmente com crianças, pois essa ficção será necessária para se expressar necessidades de diferentes dimensões e para se pensar soluções possíveis. Ou seja, a experiência corretiva vem através do lúdico e do livre brincar, que quebra as resistências dos pensamentos, sentimentos e comportamentos conservados, considerando-se que a expressão infantil naturalmente já é lúdica desde as primeiras fases de indiferenciação e diferenciação da Matriz de Identidade, como afirma Kaufman (1978). Partimos dessa ideia tanto nos atendimentos presenciais como nos on-line. Seria uma experiência corretiva no sentido da filosofia budista, da busca pela ação correta, uma ação assertiva. Também no sentido, de acordo com Alexander e French (1946/1956), de uma "experiência emocional corretiva", ou seja, da reexposição do paciente a situações emocionais ainda não superadas e conflitivas, em condições mais favoráveis e protegidas num setting terapêutico, não sendo suficiente apenas uma compreensão intelectual de seu problema, e sim uma compreensão vivida e sentida. E ainda no sentido de uma ação corretiva de maternagem, segundo Widlöcher (1962/1970), na qual o terapeuta exerce uma função materna de continência afetiva e de facilitar escolhas mais positivas e saudáveis no exercício dos papéis. 
Apesar das tecnologias e de ouvirmos e/ou vermos o outro por uma telinha, percebemos que há aproximações referentes ao processo de humanização entre o ambiente virtual sincrônico ("presencial conectado") e o presencial, como a valorização do acolhimento, escuta qualificada, expressividade e corporeidade, focos das abordagens fenomenológicas existenciais e humanistas centradas no sujeito, nas subjetividades, nos processos instituídos/constituídos, mas também instituintes/ constituintes. No atendimento com crianças, por exemplo, seguiremos as conservas sociais de modelos padronizados, os protocolos, os termos de compromisso, atentaremos às classificações do psicodiagnóstico, realizaremos anamnese, entrevistas e exames técnicos, mas também teremos abertura para o ato criativo, o inusitado, o intuitivo, os compartilhamentos coconscientes e coinconscientes, as surpresas das trocas que emergem em relação e o reconhecimento de si no outro e viceversa. Os personagens atuam baseados nas regras prévias de convivência, mas estas também são flexibilizadas, para dar espaço às verdades existenciais e às possibilidades de Ser e Existir.

O objetivo deste trabalho é refletir sobre o método psicodramático com crianças na psicoterapia individual on-line, abordando o constructo télico espontâneo, as etapas da sessão e as ferramentas, como o sandplay psicodramático através do onlinesandtray.com.

\section{DESENVOLVIMENTO: INFÂNCIAS EM AÇÃO ON-LINE}

Nos atendimentos psicoterápicos on-line com crianças, identificamos possibilidades terapêuticas adaptativas e significativas, bem como dificuldades na sustentação do conflito, da continência afetiva, da privacidade e confidencialidade. Uma criança mais ativa tende a se movimentar levando o celular consigo para nos mostrar a casa, seu quarto e animais de estimação, por exemplo. Com as menos ativas, será importante que proponhamos certo aquecimento corporal para despertar a motivação. Caso ela se desinteresse, corremos o risco dela desligar a ligação, desaquecendo-se, ou até da própria conectividade falhar por instabilidade. O virtual é real e é um presencial conectado à distância, então observamos sempre a expressão facial e corporal, enquanto sinalizadores e indicadores de como ela está se sentindo.

Consideramos que a teoria socionômica moreniana traz conceitos filosóficos embasadores necessários à fundamentação da prática à distância, articulada por suas técnicas psicodinâmicas. São essenciais as noções das teorias da espontaneidade e criatividade, da ação, da cena, do momento, dos papéis e da matriz de identidade, bem como as técnicas que mais utilizamos (duplo, espelho, inversão de papéis, solilóquio, entrevista no papel, concretização, maximização, presentificação, interpolação de resistência, eco/ repetição e zoom/panorâmica), e as mais exploratórias (como átomo social, psicodrama interno, dramatização internalizada e dramatização em cena aberta). Exemplificando, quando trabalhamos on-line com desenhos livres ou temáticos, um recurso terapêutico utilizado por todas as abordagens, damos as consignas mais pausadamente. Ao findar sua arte no papel ofício, a criança nos mostra a imagem pela tela ou tira uma foto e nos envia por mensagem, para, em seguida, nos contar a história e o título do desenho. Também têm sido utilizadas ferramentas digitais de desenho, como o google jamboard. Depois, intuitivamente partindo da relação, vem a aplicabilidade espontâneo-cocriativa das técnicas psicodramáticas, como a entrevista no papel de cada personagem, de cada detalhe, bem como a interação entre eles, o que amplia a percepção do significado daqueles símbolos desenhados.

No contexto on-line, no qual os contextos social, grupal e psicodramático se encontram, as três etapas da sessão aquecimento, dramatização e compartilhamento continuam sendo delineadas e se intercruzam; porém, existem especificidades no "aquecimento logístico" que envolvem o campo tecnológico. Precisamos levantar, inicialmente, as orientações necessárias sobre a ferramenta ou o aplicativo escolhidos para a videochamada (Whatsapp, Zoom, Meet, Whereby etc.). Para garantir a privacidade, podemos lançar mão do uso de fone de ouvido, áudios, tablet, chats, mensagens, bilhetes, desenhos, dentre outras opções cocriadas com a própria criança ou sua família. Será salutar pactuar um local sem ruídos, em virtude da confidencialidade e da concentração. Para atender crianças da primeira infância ( 0 a 3 anos), sugerimos que um dos pais ou responsáveis seja o terapeuta ou ego auxiliar com regularidade. Da segunda ( 4 a 6 anos) e terceira infância ( 7 a 12 anos), recomendamos que seja avaliado o grau de autonomia, assim algumas precisarão apenas do apoio inicial de um adulto para organizar a logística dos aparelhos e em seguida poderão seguir a sessão individual. Além do prévio consentimento esclarecido, em todos os casos de atendimento a menores de idade, um responsável deverá estar em sentinela num cômodo próximo, caso haja alguma emergência. 
Em nossa experiência presencial com crianças de 0 a 3 anos ( 1 ano e 8 meses foi a mais jovem; as demais tinham 3 anos), a terapia era focada em estimulações precoces, exploração do ambiente, limites e regras, jogos de encaixe, cores e formas, relaxamentos, desenhos e brincadeiras livres ou com famílias de bonecos. Alguns autores têm apontado que, para essa faixa etária, o melhor pode ser fazer terapia apenas com os pais, como sinaliza Filipini (2014). A orientação de pais seria muito bem-vinda, pois a criança nessa idade não ficaria parada diante da tela on-line sem o apoio dos pais ou responsáveis, caso eles demandem o acompanhamento e a avaliação psicológica da criança. Concordamos e não descartamos esta posição, o que nos faz lembrar que, quando Zerka Moreno (1958/1975) se refere a psicodrama de bebês, na realidade seu trabalho é desenvolvido com as mães e seus bebês no colo, e os egos auxiliares se colocam no lugar da criança e tentam fazer duplos dela, para ampliar a compreensão do próprio comportamento materno. Será importante, quando formos demandados a atender psicoterapicamente a primeira infância, observarmos de qual demanda estaremos cuidando e de quais teremos limitações em atender às expectativas, especialmente no ambiente on-line.

A presente autora, e.g., Strauch (2020), afirma que, ao depararmo-nos com a sensação de trava no processo, podemos nos perguntar "o que faríamos no presencial?" e, em seguida, fazer a adaptação. Percebem-se dificuldades adaptativas em alguns casos, principalmente no que se refere a evitar interrupções no processo terapêutico, mas é possível pactuar corresponsabilidades com os pais/responsáveis, deixando elucidado o suporte familiar necessário e efetivo no apoio logístico afetivo do cuidado, bem como os limites anunciados para garantir o sigilo da terapia da criança. Em determinado momento inicial, é importante adultos organizarem a logística das tecnologias, separarem os materiais que serão utilizados em sessão ou intervirem em surtos emergenciais; porém, num segundo momento, será importante darem espaço para que a criança possa se expressar livremente, sem interferências da presença destes adultos cuidadores.

Durante o desenvolvimento da sessão, percebemos que há momentos nos quais guiamos, enquanto diretores, propondo um jogo, uma brincadeira, a leitura de um livro infantil, a montagem de uma imagem ou história na caixa de areia, um relaxamento, uma internalização, uma contação de cena temática ou livre, de sonho ou pesadelo, de cena positiva ou negativa (teatro da vida). Noutras ocasiões, o Eu Curador Interno da criança é quem nos guia, com sua natureza espontâneo-criativa, escolhendo e sinalizando as atividades realizadas. Podemos até propor um meio ou recurso terapêutico, mas devemos respeitar que a criança é quem trará o conteúdo, o conflito e o caminho a ser seguido em direção às saídas reais e simbólicas, de acordo com suas verdades existenciais concretas e imaginárias.

Experimentamos a montagem de cena em caixa de areia de duas formas, ambas com uma cliente de 10 anos, que chamaremos de Jujuba. Numa primeira tentativa, trabalhamos com o método do sandplay psicodramático (Ramalho, 2007, 2010,2011), de temática “quem sou eu e como estou no momento?". Com o celular móvel, a terapeuta mostrava as miniaturas de seu consultório e a criança escolhia as peças que a representariam, ditando onde colocá-las. Depois de apresentar os personagens, criar a história e o título, a terapeuta pedia que ela escolhesse qual seria entrevistado, um em seguida de outros no role playing, e também eram promovidos confrontos e diálogos entre eles. Num segundo formato, trabalhamos com a adaptação digital no onlinesandtray.com (Oaklander Training, 2020), a qual detalharemos a seguir.

\section{METODOLOGIA E DISCUSSÃO: A SOCIONOMIA E SEUS MÉTODOS DE AÇÃO DRAMÁTICA}

Durante alguns meses foram suspensos os atendimentos presenciais devido aos riscos do coronavírus, o que aumentou a ansiedade, os medos, a dificuldade de atenção e concentração e a sensação de isolamento nas crianças que estava acompanhando. Começamos os atendimentos on-line através de pactuações por mensagens e enviamos os termos de consentimento livre e esclarecido para pesquisa, a serem assinados digitalmente por e-mail. No atendimento de uma criança de 3 anos, optamos por suspender o atendimento individual e passamos a realizar orientação de pais nos papéis materno, paterno e da relação de casal, por preferência dos genitores, já que a criança fazia muitas birras e resistências para ficar sentada ou manter-se no colo deles diante do computador, mesmo que eu tivesse orientado a ficarem num ambiente com movimentação mais livre, como o quarto da criança. Em outro atendimento, com uma criança de 8 anos, trabalhamos os medos, intensificados na pandemia, da morte, de injeção, do fogo, de bandidos, de armas e balas perdidas, através das cartas do baralho Jogo Arremedo, da técnica da cadeira vazia e do uso de travesseiros como objeto simbólico 
para concretização e enfrentamento dos medos. Este menino trouxe o "poder da mente" como parte mágica e poderosa do seu personagem, dramatizando e maximizando com o corpo de pé o diálogo vivo diante de cada medo apresentado.

Nesta pesquisa-ação qualitativa (Nery et al., 2006), trazemos o breve estudo de caso de Jujuba, 10 anos, na abordagem sociopsicodramática bipessoal on-line, relatando a sessão na qual foi utilizado o sandplay psicodramático (Ramalho, 2007, 2010, 2011) adaptado na ferramenta digital onlinesandtray.com (Oaklander Training, 2020).

Já na primeira sessão on-line com ela, percebemos que quando a criança estiver cabisbaixa e calada, devemos ficar atentos se há adultos ao redor para repactuar o direito ao ambiente reservado, e que também podemos trabalhar com iniciadores corporais. Devido a deficiências cognitivas leves e dificuldades de compreensão das consignas mais complexas, solicitamos apoio inicial da genitora de Jujuba apenas para colocar no desktop abertos, ao mesmo tempo, a vídeochamada da sessão pelo app Google Meet e o compartilhamento da tela do site da caixa de areia digital. Em seguida orientamos a cliente sobre o banco de imagens para a criação de uma história livre, começando por "era uma vez". Percebemos que ela começou a montar diferentes cenários, como um filminho, e que teria dificuldade em salvar as cenas, por seu perfil mais ativo e acelerado. Por isso, como estratégia de direção, fomos fazendo o printscreen de cada parte, salvando e guardando no computador para intervenções posteriores.

A história nos remeteu à adoção da cliente, à perda dos pais biológicos, que ela não conhece, ao falecimento do pai do coração, a seus desejos de proteção e de ser cuidada por uma figura paterna, e à possibilidade de realização simbólica em realidade suplementar, enquanto arte de curar, como reforçam Moreno et al. (2001). Vimos interação em uma cena aberta imaginária sendo concretizada digitalmente e vivenciada visualmente (Fig. 1):

Era uma vez um céu nublado, mas com sol, uma princesa que vivia sozinha e uma borboleta voando. Ai chegou um rei e as plantas cresceram para eles terem um lugar mais reservado para conversarem. Seu pai construiu uma casa para morarem e ele a deu muitas flores, infinitas rosas. O céu deixou de ficar nublado enquanto ele lhe dava esses presentes. Um dia eles foram para um sitio, curtir uma festa com fogueira de São João. Outro dia foram passear de carro. Subiu um muro de proteção na casa deles. E por fim, foram morar num castelo encantado.
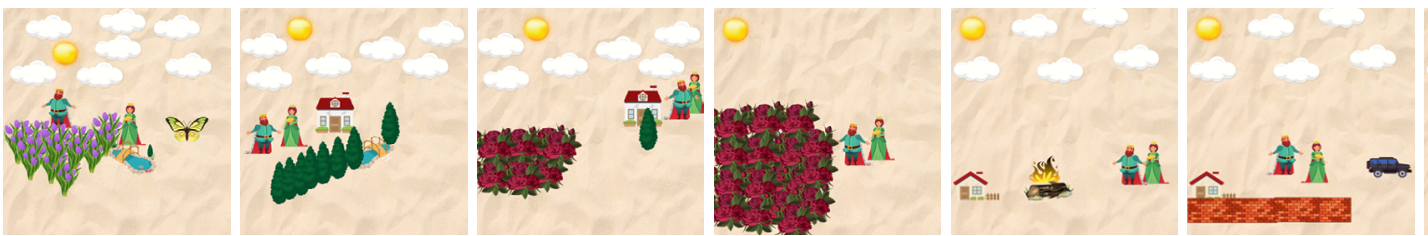

Figura 1. Imagens do on-linesandtray (psicodramático) com cliente Jujuba, 10 anos.

A criança Jujuba começou dando asas à sua imaginação. Foi vivenciando no "como se" as cenas desejadas na vida real, seu desejo de liberdade e de "morar na roça ou num sítio", a vontade de conviver com uma figura paterna perdida, e voltou ao mundo encantado no final, como mecanismo de proteção para lidar com as faltas do cotidiano. Percebemos que, no presencial, o contato com a areia torna a experiência mais profunda, porém a areia digital não impossibilitou o mergulho no faz de conta e no inconsciente. Para Ammann (2002), o Jogo de Areia mobiliza e confronta o cliente com seus lados consciente e inconsciente e vai, ao mesmo tempo, mostrando, em sentido construtivo e de religação, suas possibilidades e capacidades para o desenvolvimento, entrando em cena como um todo, psíquica e fisicamente. Ele joga um jogo sério e significativo, criando seu mundo dentro do espaço concentrado.

Seu título foi "O sonho do sítio no mundo encantado". De fato foi um sonho muito bonito, e ela é sempre muito sonhadora e distraída, como a borboleta voadora que some. Uma parte se realizará no ano seguinte, pois ela e sua genitora do coração voltarão a morar no interior de outro estado, mais próximo de outros familiares, tendo mais contato com a roça e o cuidado de animais, como ela gosta e pelos quais é encantada.

Houve o desempenho de ambos os papéis, da filha princesa e do pai rei, por parte da cliente. Durante as inversões, ela pôde ouvir do pai internalizado desejado dentro dela o que ela precisava, e pôde também responder e colocar para fora 
o "não feito" e o "não dito" na vida real. Quando utilizamos o duplo espelho do papel do pai, com as mãos na cabeça e depois no coração, falamos do sentir muito por estarmos distantes, mas que a amamos muito. Seguimos a ideia de correção dos papéis, conforme Widlöcher (1962/1970), na qual um doublé vai exercendo uma força resistente, respeitando o clima difícil do conflito existencial, e depois atua, o que equivale a um encorajamento e uma aprovação; e isso dá à criança maior segurança na representação de seu próprio papel e na descoberta de novas atitudes. Essa ação corretiva vem do treinamento terapêutico da espontaneidade. O essencial do método é a improvisação dramática (espontaneidade e criatividade em ação) e o campo psicológico télico que ela determina.

Segundo Slade (1958/1978), geralmente as crianças menores se expressam, no faz de conta, mais através do "jogo projetado", ou seja, com uso de objetos/imagens para representarem a si, ao outro e ao ambiente. Já as maiores, além do projetado, passam também ao "jogo pessoal”, com uso do próprio corpo para representar os personagens envolvidos, dando uma dimensão tridimensional à experimentação dos papéis. No sandplay psicodramático a expressão é de um jogo projetado nas miniaturas (contexto presencial) ou nas imagens digitais (contexto virtual: on-line e síncrono); porém, pode-se passar à dramatização em cena aberta num jogo pessoal. A interpretação da dinâmica apresentada na caixa de areia, seja esta concreta ou digital, durante a representação simbólica, parte de uma visão fenomenológica existencial centrada no sujeito em relação.

\section{CONSIDERAÇÕES FINAIS: COMPARTILHAMENTOS...}

Consideramos que o ano de 2020 foi um divisor de águas, no sentido de que a partir dele teremos muitas contribuições do psicodrama clínico no universo da web. Trouxemos aqui alguns compartilhamentos que ilustraram a intensificação do trabalho virtual e refletimos sobre os desafios do método psicodramático com crianças na modalidade individual on-line. Apesar das dificuldades e especificidades, tal contexto mediado por tecnologias não inviabiliza o desenvolvimento da relação terapêutica. As contraindicações têm relação com o grau de autonomia da criança ou interdito, a instabilidade ou ausência da conectividade e a avaliação das condições éticas de privacidade e confidencialidade.

O constructo télico é permeado por ferramentas digitais, mas continua com enfoque na cocriação, na espontaneidade e na expressividade do corpo em diferentes modos. Estamos sempre em processo de adaptação decorrente das mudanças contemporâneas velozes.

O conjunto de teorias e técnicas morenianas contribuem para trabalhar de forma dinâmica, simbólica e lúdica os conflitos infantis, em consonância com a política da afetividade e da liberdade com responsabilidade defendida por Moreno. Esperamos que novas pesquisas e estudos de casos identifiquem quão incrível é o Eu Curador Interno da criança, pois ele nos encanta, nos contagia e nos guia com sua natureza espontâneo-criativa, em direções antes impensáveis racionalmente no mundo das adultices.

Sejam a internet ou outros meios de comunicação conectando nossas vidas, estaremos sempre abertos às oportunidades de aprendizado, experimentando novas formas de expressão, de nos adaptar e resolver os problemas à medida que estes vão se modelando. E queremos estar em movimento junto às diferentes infâncias em ação.

\section{DISPONIBILIDADE DE DADOS DE PESQUISA}

Todos os dados foram gerados ou apresentados neste estudo.

\section{FINANCIAMENTO}

Não se aplica.

\section{AGRADECIMENTOS}

Não se aplica. 


\section{REFERÊNCIAS}

Ammann, R. (2002). A Terapia do Jogo de Areia: Imagens que curam a alma e desenvolvem a personalidade (Marion Serpa, Trad.). Paulus. (Obra original publicada em 1934).

Coutinho, D. (2019, 11 de agosto). Geração do quarto: Estilo de vida que tem levado ao adoecimento emocional. ESHoje. https://eshoje.com.br/geracao-do-quarto-estilo-de-vida-que-tem-levado-ao-adoecimento-emocional/

Cruz, J. (2010, 20 de agosto). Telepsicodrama é recurso didático para professor. Agência USP de Notícias. http://www.usp. br/agen/?p=31558

Cukier, R. (1992). Psicodrama Bipessoal: Sua técnica, seu terapeuta e seu paciente. Ágora.

Faro, A., Bahiano, M. A., Nakano, T. C., Reis, C., Silva, B. F. P., \& Vitti, L. S. (2020, 1 de junho). COVID-19 e saúde mental: A emergência do cuidado. Estudos de Psicologia, 37, e200074. https://doi.org/10.1590/1982-0275202037e200074

Fleury, H. J. (2020). Psicodrama e as especificidades da psicoterapia on-line. Revista Brasileira de Psicodrama, 28(1), 1-4. https://doi.org/10.15329/2318-0498.20203

Kaufman, A. (1978). O jogo em psicoterapia individual. Revista da Febrap, 2, 82-86.

Moreno, J. L. (1974). Psicoterapia de grupo e psicodrama: Introdução à teoria e à práxis (A. C. M. Cesarino Filho, Trad.). Mestre Jou. (Obra original publicada em 1959).

Moreno, J. L. (1975). Psicodrama (Álvaro Cabral, Trad.). Cultrix.

Moreno, Z. T. (1975). Psicodrama de Crianças (E. F. Alves, Trad.) Vozes. (Obra original publicada em 1958).

Moreno, Z. T., Leif, D. B., \& Rutzel, T. (2001). A realidade suplementar e a arte de curar. Ágora.

Nery, M. D. P., Costa, L. F., \& Conceição, M. I. G. (2006). O sociodrama como método de pesquisa qualitativa. Revista Paidéia, 16(35), 305-313. https://doi.org/10.1590/S0103-863X2006000300002

Ramalho, C. M. R. R. (2007). Sandplay psicodramático: O psicodrama aplicado à caixa de areia. Cadernos de Psicologia, 9(2).

Ramalho, C. M. R. R. (2010). Sandplay psicodramático: Um jogo na interface do psicodrama com a psicologia analítica. Revista Brasileira de Psicodrama, 18(2), 107-117. http://pepsic.bvsalud.org/scielo.php?script=sci_arttext\&pid=S0104$53932010000200007 \& \operatorname{lng}=$ pt\&tlng=pt

Ramalho, C. M. R. R. (Org.). (2011). Psicodrama e Psicologia Analitica: Construindo pontes. Iglu.

Filipini, R. (2014). Psicoterapia psicodramática com crianças: Uma proposta socionômica. Ágora.

Oaklander Training (2021). Online Sand Tray by Dr. Karen Fried. https://onlinesandtray.com/

Slade, P. (1978). O jogo dramático infantil (Tatiana Belinky, Trad., Vol. 2). Summus. (Obra original publicada em 1958).

Strauch, V. R. F. (2020). Psicoterapia Infantil on-line numa visão socionômica. In J. P. C. Santana et al. (Org.), Interfaces dos Atendimentos Psicológicos On-line. Literatura em Cena.

Widlöcher, D. (1970). Psicodrama Infantil. Vozes. (Obra original publicada em 1962). 